\title{
AUGUSTO COMTE E AS ORIGENS DO POSITIVISMO
}

\author{
(Continuação)
}

\section{II \\ ORIGENS E DESENVOLVIMENTO DA POLITICA DE AUGUSTO COMTE}

O positivismo é contemporâneo das primeiras consequiências da grande crise que marca a transição dos séculos XVIII e XIX. O próprio Augusto Comte confessa, como já vimos, que a sua doutrina emana da revolução, embora acrescenta êle, defira "profundamente das escolas revolucionárias" (76). "O positivismo, é ainda Comte quem o diz no seu Système de Politique Positive "desde o seu nascimento soube igualmente aceitar a sucessão de De Maistre e a de Condorcet" (77).

As influências que vão pesar sôbre o destino da doutrina de Comte quem o diz, no seu Système de Politique Positive "desde o continuará o pensamento francês do século XVIII, do qual Condorcet é um dos mais altos representanies e de outro, receberá a influência dos autores que representam, no alvorecer do século XIX, a crítica da Revolução, aquêles que, no dizer de Léon Brunschvicg, procurariam estabelecer uma "oportunidade social para um movimento retrógado" (78). A antinomia que está na herança que o positivismo recebe é, assim, indicação preciosa para a compreensão do sentido das vicissitudes da doutrina de Augusto Comte.

E necessário também não esquecer que no momento em que Comte elaborava a sua filosofia, a política conservadora do passado já perdera o seu sentido. Processava-se, porém, entre os diferenies elementos, cujos interêsses haviam sido prejudicados pelo advento da Revolução, e entre aquêles que haviam tirado proveito da aventura napoleônica, uma reação contra is idéias dos filósofos

(76) - COMTE (A.) - Lettre philosophique sur la Commémoration Sociale, in Testament d'Auguste Comte, p. 240 h.

(77) - COMTE(A.). - Bysteme de Politique Positive, t. II, p. 178.

(78) - BRUNSCIVICG (L.). - Le Progres de la conscience dans la Philosophle Occidentale, vol. II, p. 627. 
do século XVIII que a Revolução, inicialmente havia adotado. Retomava-se em novas bases a defesa do princípio da autoridade que havia passado por tão diferentes oscilações e pretendia-se, como observa Brunschvicg, "restaurar, para além do presente, o passado" (79). Augusto Comte sofrerá a influência dessa corrente restauradora, primeiramente na convivência com Saint-Simon, o aventureiro da filosofia social do século XIX. êste que lega a Comte a missão de reformador, ou como diz Georges Dumas, o messianismo.

Além disso, a França sentira-se abatida depois da derrota de Napoleão e perderá o ímpeto de fôrça e entusiasmo que a Revolução, e mais tarde as vitórias napoleônicas, lhe haviam infundido. De 1815 a 1850 , o pensamento francês estará entregue a um curioso gênero de romantismo humanitário (81) que exercerá influência na política. Augusto Comte, como seu mestre Saint-Simon, não escapa ao clima dessa época. Saint-Simon, acabaria construindo "um novo sistema industrial que reservará aos sábios a missão de inflamar os seus administradores espirituais com a paixão do bem público, com um novo cristianismo que será a esperança da humanidade até o dia em que a escola transformada em Igreja se dissolvesse no ridículo que é, por uma espécie de fatalidade, inherente ao estilo Luiz Felipe" (82).

Aliás, no século XIX, o romantismo e o positivismo aparentam estar em antagonismo mas, de fato, existe entre êles um estreito parentesco. Romantismo e positivismo são impelidos pela mesma tendência. Ambos estão animados pela necessidade de aprofundar grandes realidades. $O$ romantismo pretende, como o positivismo, apreender a realidade; e sòmente crê apreendê-la pela via subjetiva enquanto que o positismo quer se construir sôbre fatos objetivos. O postulado que lhes é comum é êste: um ideal situado absolutamente fora da realidade é falso. E essa a razão pela qual tanto o romantismo como o positivismo se desviam da crítica racional do século XVIII e mergulham com entusiasmo na história.

O conceito de desenvolvimento predomina tanto no romantismo como no positivismo. O que se procura, principalmente, é eneontrar o "encadeiamento contínuo da história que o período da Aufklärưng e que a Revolução haviam quebrado. Uma inteligência mais aprofundada do passado e das condições da vida espiritual constituem parte essencial da significação das duas tendências na história do pensamento" (83). Esses traços românticos, vamos encontrá-los na filosofia de Augusto Comte e êles se apresentam

(79) - Ibidom, p. 524 .

(80 - DUMAS (G.). - La Psychologie des Denx Mossles Positivistes, pp. 2/3.

(81) - Cf. RENÉ CANAT, Ma Littérature Française au XiXe siècle, p. 95.

(82) - BRUNSCHIVICG (L.). - ob. eit... vol. II, p. Bs9.

(83) - HOFFDing (H.) - Histolre de la Phillosophio Moderne, vol. II. p. 303. 
ainda mais salientes na própria vida do filósofo. $O$ que impressiona na biografia de Augusto Comte, além do seu feitio de intelectual puro e da sua missão de "apóstolo compenetrado da grandeza do seu papel" (84), é o seu temperamento, "as aventuras de sua sensibilidade, a impotência infeliz em que se encontrava de nunca duvidar de si" (85), que faziam com que êsse antigo aluno da Politécnica de París pertencesse ainda, como muito bem observa Lucy Prenant, "à geração dos Bazard e dos Enfantin que êle despresava" (86). Este reformador, êste "salvador da humanidade que o acaso fêz nascer no momento preciso em que a historia reclama um parteiro, - sombrio, solene, envolvido no seu orgulho, não deixava de evocar Jean-Jacques, talvez mesmo René” (87).

Augusto Comte não fugiria assim à atração da reação romântica que, como é sabido, estava ligada à restauração religiosa. A medida que a sua obra se desenvolve e o seu pensamento progride é fácil verificar que sua política se aproxima cada vez mais da religião. Fácil é perceber também que essa religião tem um caráter eminentemente social. No Apêlo aos Conservadores, Comte indica claramente o sentido que tem a sua religião: ela é uma solução ao principal problema político, isto é, a conciliação da ordem e áo progresso (88), a defesa de uma ordem social que permitiria conciliar êstes dois conceitos que são, na. opinião de Comte, apenas aparentemente antagônicos. O que, desde muito cêdo Comte pretendeu, foi "fundir, em uma ciência nova e positiva, as idéias sociais originadas da especulação do século XVIII com as verdades históricas postas à luz pelos adversários desta filosofia; o problema estava nitidamente apresentado. A solução que Comte lhe dá, é a própria alma do seu sistema. Por meio de um duplo e vigoroso esfôrço, êle cria a física social. De outro lado, relaciona com o passado a idéia de progresso que Condorcet apenas havia aplicado ao futuro e isto the permite instituir uma filosofia positiva da história. Ao memo tempo, projeta para o futuro, a ordem espiritual que De Maistre apenas havia visto no passado e isto fornece-lhe o quadro de sua reorganização social (89).

(64) - PRENANT (Lucy). - Marx ot Comte, in A la lumiere du marxismo, vol. II, p. 24. Cr. ERNEST SEILLIERE, Auguite Comte, pp. 235 e 245 . Em carta a Valat, de 1825, escrevia Augusto Comte que "minha vida 6 , en resumo, um romance e um romance que pareceria bem estranho, se eu - publicasse com nomes supostos", apud H. GOUHIER, La Vlo d'A=sunte Conte, p. 9.

(85) - BRUNSCHVICG (L.) - ob. cit., vol. II, p. 541.

(86) - PRENANT (Lucy). - ob. cit., o. 25.

(87) - lbidem.

(88) - Cl. A. COMTE, Apelo gos Conservadoron, trad. Miguel Lemos. D. '73. E' curiosa a atitude dos partidários da extinta Action Francaise em relacão a Comte. $O$ Conde de Montesquiou, estudando a politica de Comte, quo err parte loi a da próprla Action Françalse, assim escreve: "... positivisme, pris dans son ensemble, est une religion. Or, sans nul doute, les catholiques n'ont que faire du positivisme en tant que religion. Que peuvent-ils alorg chereher dans Auguste Comte que leur solt utlle? Je reponds: une défense de l'ordre soclal". L. DE MONTESQUIOU, IA Byatèmo Polltique d'Augusto Comte, p. 10

(80) - LFVY-BRUHL (L.). - Is Phlowophlo d'Augnete cemte, p. 34T. 
No ardor da sua caridade filantrópica, aos poucos, Augusto Comte abandonaria a tradição científica dos Enciclopedistas, "le vantando contra a capela de seu mestre Saint-Simon um novo templo construído segundo o mistério de uma fantasia diferente" (90). Aliás, já desde os tempos em que cursava a Politécnica, Comte "compreendera a insuficiência de uma instrução científica limitada a primeira fase da positividade racional, que se estende apenas ao conjunto dos estudos orgânicos" (91). Sentirá ainda "antes mesmo de haver deixado êsse nobre estabelecimento revolucionário, a necessidade de aplicar as especulaçõs vitais e sociais, a nova maneira de filosofar que tinha aplicado em relação a assuntos mais simples" (92).

A politica deveria, pois, presupor uma ciência social, assim como as diferentes técnicas supõem diferentes ciências, com objetivos precisos. A mesma convergência mental que determina a certeza e a unidede do pensamento científico, transportada para o domínio social requer a existência de uma doutrina ou de um sistema de crenças que deve ser homogêneo e comum a todos os homens. Admitida esta doutrina, impunha-se a instituição de um poder espiritual cuja função consistisse também em espalhar a doutrina e assegurar-lhe permanência. Dai deriva a necessidade de uma igreja que no caso, será uma igreja em que os sábios oficiarão como sacerdotes. Existe assim na doutrina de Augusto Comte, mais de uma semelhança com o platonismo. "O poder espiritual - escreve Augusto Comte - tem por destino próprio o govêrno da opinião: isto é, o estabelecimento e a manutenção dos princípios que devem presidir as diferentes relações sociais. Esta função geral se divide em tantas partes quantas são as classes distintas de relações, pois não há, por assim dizer, nenhum fato social no qual o poder espiritual não exerça uma certa influência quando êle é bem organizado" (93).

Este platonismo de Comte lhe advém de influência romântica (94). A admiração e simpatia que Comte sempre demonstrou pelo catolicismo, sobretudo pela idade de ouro do catolicismo que é a Idade Média, percorre tôda a obra de Comte. No Curso de Filociofia Positiva há um trecho relevador das inclinações de Comte. "Profundamente imbuido, desde muito cêdo, como eu o devia ser, de espírito revolucionário, considerado em todo o seu alcance filosófico, não deixo de confessar, com sincero reconhecimento e sem incorrer em nenhuma acusação de inconseqüência, a salutar influência que a filosofia cotólica, apesar da sua natureza evidenmente retrógrada, exerceu ulteriormente sôbre o desenvolvimento

(90) - BRUNSCHVICG (L.). - ob. cit., vol. II, p. 541.

(81) - COMTE (A.). - Cours do Philosophie Positive, vol. VI, p. VI.

(92) - COMTE (A.) - pp. VI, VII.

(93) - COMTE A.) - Considerations sur le pouvoir spirituel, in système de Politique Positlve, apéndice, p. 194.

(94) - Cf. E. SEIJLIERI, Lo Romantismo, pp. 18/26 e BRUNSCHVICG, ob. cit., vòl. II, p. 382 . 
de minha própria filosofia politica, sobretudo pelo célebre tratado Do Papa, não sòmente facilitando-me em meus trabalhos históricos uma sã apreciação geral da Idade Média, mas até fixando mais a minha atenção direta sôbre condições de ordèm eminentemente aplicáveis ao eutado social atual embora concebidas por um outro estado" (95). Influenciado por De Bonald e Joseph de Maistre, Augusto Comte, assim como já o fizera Saint-Simon, pretende resolver a crise social do seu tempo, transformado "os quadros da hierarquia eclesiástica, o prestígio do poder espiritual em benefício da civilização moderna e do espírito científico, isto é, para falar exatamente, (Saint-Simon e Comte) põem vinho novo em velhos odres. Semelhante tentativa pode parecer paraxodal, já no seu anunciado. Ela não deixa de expressar, no entanto, (...) uma exata exigência do tempo que consiste na sintese dos séculos XVIII e XIX, do progresso racional e da ordem romântica; aliás, sem atender para êste paradoxo, duvidamos que se possa entender as extraordinárias vicissitudes que o saintsimonismo e o positivismo apresentam" (96).

E mister não perder de vista as circunstâncias históricas do aparecimento da filosofia positiva para compreender o sentido que ela toma na primeira metade do século XIX.

"O período de 1815 a 1848 assiste a uma polulação de sistemas sociais. Depois da grande perturbação da Revolução e do Império, sentia-se necessidade, escreve Roger Picard, de reconstruir a sociedade, de unir os espíritos e os corações. Esperanças imensas, uma exaltação geral dos espíritos, uma fecundidade de imaginação construtiva dão ao movimento intelecual dêste período o seu aspecio característico" (97). Poetas e pensadores, todos se dispõem a procurar a fórmula que há de dar unidade de espírito que lhes parecia tão necessária à volta de uma nova e de uma verdadeira paz social. "Os escritores sociais que lêem os poetas de seu tempo, deixam-se ganhar pelo seu lirismo, pela sua eloqüencia, pela sua imaginação poética, pela sua maneira de estudar as questões sociais, pelo seu gôsto pelas grandes sinteses históricas, pela ousadia de sua maneira de encarar a futuro, assim como pelo entusiasmo que têm em expor as suas idéias e de o fazer num estilo colorido que permite considerá-lo como romântico" (98). Esses anos de perturbação social haviam trazido para Europa do princípio do século XIX, uma necessidade de revisão de idéias e até de maneiras de sentir. A todos se impunha a necessidade de procurar uma nova unidade espiriual. Essa foi também a ambição de Saint-Simon e de Augusto Comte" (99).

(85) - COMTE (A.). - Cours de Philosophie Positive, vol. IV, pp| 96/97, nota 1 .

(96) - BRUNSCHVICG (L.). - Le Progrès do la Conscionce danś la Phllosophio occldentale, vol. II, p. 534 .

(97) - PICARD (Roger). - Lo Romantismo social, p. 289.

(98) - Ibidem.

(89) - PICARD (G.) - p. 79. Cf. R. HUBERT, comte, p. 26. 
Nem todos souberam ou puderam, no entanto, expressar com a devida clareza, os matizes dessa crise de transição entre dois mundos tão diferentes quanto o eram o Antigo Regime que a Revolução destruiu e o que burguesia organizaria. Talvez, como diz Carl Schmitt, a "natureza essencialmente estética do romantismo, o tornasse inapto a qualquer atividade politica (100), e dai as dificuldades de uma política feita pelos críticos românticos. Embora participante do clima romântico, Comte, porém, graças a sua formação científico-matemática, dará uma visão mais exata de sua época. E por isso que parece justificada a observação de Cantecor quando diz que "a obra de Comte fecha a era da ciência e inaugura um período novo, o da filosofia social científica" (101). Comte podia superar o próprio preconceito científico enquanto os românticos, por não terem uma convivência tão íntima com a própria prática científica, ainda se submeteriam respeitosos à ciência.

A filosofia positiva aplicada à política - assim pretendiam os filósofos dêsse momento - conduzirá a humanidade ao sistema social mais adequado à sua natureza. A filosofia positiva ultrapassaria, assim, em homogeneidade, em extensão e estabilidade, tudo que o passado poude imaginar" (102).

O período em que transcorre a vida do filósofo, principalmente a sua adolescência e mocidade (1812-1832) é "um mundo que os revolucionários tornaram infinitamente elástico" (103). Napoleão consolidara a obra que a burguesia iniciara com a $\mathbf{R e}$ volução de 1789. O imperador tivera todo apôio da burguesia onquanto correspondera ès necessidades históricas e revolucionárias desta classe, na manutenção da ordem que ela implantara. Mas, logo que a burguesia se sentiu assaz forte e segura para prescindir de um chefe, tratou de prosseguir na sua rota, alijando aquêle que ela humildemente seguira e que ela mesma transformara em herói. Sem o apôio dos camponeses, a ditadura jacobina, ala avançada da própria burguesia, cairia, e, em 9 de Termidor, a grande maioria burguesa, moderada, marcaria o seu pleno triunfo revolucionário. Durante o Império, esta burguesia moderada, enriqueceria e fortalecer-se-ia. Com a restauração dos Bourbons, ela firmaria definitivamente, sobretudo depois dos Cem Dias, o seu prestígio econômico e político. Quando, em 1827 e 1828, a política teológica de Carlos $\mathbf{X}$ tentou reavivar o passado feudal, ainda uma vez a burguesia apelaria para o auxílio das massas populares para evitar a retrogradação (104): Esta situação explica, em parte, a obra de Saint-Simon e de Comte. A revolução fôra feita com a massa, mas os chefes eram burgueses. A sua principal con-

(100) - SCHMITT (Carl), Romantiome Rolltiqua D. 145.

(101) - CANTECOR (G.). - Comte. p. 32.

(102) - COMTE (A.). Coure de Phliosophle Positive, t. VI, p. 5A2.

(103) - GOUHIER (H.). - La Jelnesse d'Augusto Comte ot Ia formation an positivinme, vo!. $I$, p. 115. (104) - BEER (Már). Hintoria Goneral dol Soclalismo $y$ de las luchas ocialos,
vol. II, p. S4. 
quista fôra a igualdade jurídica. Os direitos sagrados do homem tomaram, desde logo, um aspecto religioso (105) e o sentido de luta de classe que nessa tendência se continha desapareceu em benefício de uma vaga fraternidade que acabou simplesmente como epígrafe para frontões de edifícios públicos (106). Os verdadeiros beneficiados e triunfadores da Revolução, "foram, como escreve Mayer, os capilalistas, os inspetores do exército e deputados cujas manobras, freqüentemente imorais, os levaram a uma acumulação de capital; com isto se produziu um novo impulso na indústria e no comércio. Segundo Mathiez, as ladroeiras feitas durante o Diretório prepararam o desenvolvimento industrial que se produziu sob o Consulado e o Império. O diretório se baseava na Constituição do ano III que voltou a estabelecer, mediante o sufrágio censitário, o domínio da classe média rica e desenvolveu uma política intermediária entre as aspirações democráticas dos jacobinos e a restauração monárquica defendida pelos emigrados. $O$ esfôrço de Babeuf, que considerava 'a Revolução como uma guerra entre os patrícios e os plebeus, entre ricos e pobres, foi inútil. Sua rebelião, que aspirava por uma sociedade socialista e pela nacionalização da propriedade, fàcilmente foi sufocada. Como o sufrágio dependia do pagamento de impostos diretos, os trabalhadores da cidade e do campo não podiam votar (107). Aproximadamente milhão e meio ou dois milhões de eleitores, num total de sete milhões, viram-se privados, dêste modo, de influência política" (108).

Do equilíbrio de fôrças que se processou então entre os revolucionários, àquêles a quem Augusto Comte chamará de representante da política metáfísica e os representantes da reação, os sectários da política teológica, aproveitam-se os generais e, com Napoleão surge a ditadura militar que proporcionará à burguesia, como já dissemos, ocasião para consolidar não sòmente os seus negócios mas o seu prestígio político. O Código Napoleônico é o marco da vitória da burguesia e, com êle a França transita do Antigo Regime para o regime burguês. Napoleão soubera conciliar os interêsses das duas facções, a do passado e a que ascendera ao poder, graças à Revolução. Durante os Cem Dias, liberais, artesãos e jornaleiros demonstraram preferí-lo aos Bourbons reacionários (109).

Napoleão deixaria, no entanto, como herança, duas Franças: a França católica, monárquica, que encarnou a reação e a França

\footnotetext{
(105) - MAYER (J. P.). - Trajectoria del Pensnmiento Politico, p. 223.

(106) - Ibidem. Cf. ALBETRT MATIHIEZ, La Revolution et I'Eglibe, p. 22.

(107) - î̀ sintorncitica a atitude de Boissy d'Anglas, quando na preparação da Constituição do Ano III, dizia: "Deverfamos ser governados por homeng melhores: e estes são os mais instrujdos e os mais interessados na manutençāo da lei. Pois bem, com muitos poucas exceçōes, somente se encontrarão homiens destes a não ser entre os proprietarios que, por serem proprietários, estāo ligados ao seu yais, as leis que protegem sua propriedade e a paz social que a preserva", apud HAROLD LASKI. ISI Liberalismo Europeo, p. 327.

(108) - MAYER (J. P.). - ob. cit., p. 224.

(109) - MATER (J. P.) - ob. cit., p. 228.
} 
"revolucionária". A Restauração foi um pequeno interregno de compromisso. A monarquia de Julho, iniciada no momento em que começa a publicação do Curso de Filosofia Pasitiva, marca o início do reinado dos banqueiros. Laffitte, ao acompanhar seu compadre Luiz Felipe ao "Hotel de Ville" pronunciaria a célebre frase - agora começa o reinado das banqueiros - em que trairia o sentido que tomava agora a Revolução. O sistema de Guizot, todo êle está contido também na famosa frase: Enrichissez vous! Será êste o lema da nova época. A burguesia representada por homens como Guizot, estava "tão longe de convidar as massas a participar do Govêrno, como o havia estado o terceiro estado em 1791. Antes de 1816, a burguesia já havia conseguido estabelecer um sufrágio limitado, de acôrdo com uma qualificação baseada na propriedade. A Constituição de 1830 voltou a êste sistema de sufrágio censitário. Quando Luiz Felipe, - o Rei Burguês - decidiu passear de cartola e guarda-chuva pelas ruas de París, revelava-se a nova tendência comercial que se sentia em tôdas as esferas. Este homem era o representante do juste milieu, tão afastado de qualquer tendência audaz e original como de tôda espécie de iđéias heróicas" (110). Ninguém descreveu melhor o sistema que então se inaugurara, do que Alexis de Tocqueville quando disse que a "classe média quando se tornou govêrno, o considerou como uma espécie de indústria privada" (111).

Enquanto os financeiros tomavam conta do poder, os aristocratas comentavam em têrmos de estética literária, o desêjo que alimentavam de uma volta ao passado. Mas o passado nunca volta. O Gênio do Cristianismo, de Chateaurbriand é um índice do romantismo político da época em que Augusto Comte viveu. "O mundo degenerado - escrevia o Visconde de Chateaubriand clama por uma segunda pregação do Evangelho; o cristianismo se renova e sai vitorioso do mais terrível dos assaltos que o inferno já the proporcionou. Talvez aquilo que tomamos como sendo a queda da Igreja seja apenas a sua ressurreição. Ela perecia na riqueza e no repouso; ela não se lembrava mais da cruz; a cruz reapareceu, ela será salva" (112). Se o Visconde revelava o desêjo de ressuscitar o cristianismo, Saint-Simon - outro aristocrata procurava, nesse mundo novo que a revolução havia engendrado. criar um novo cristianismo, fundementado no poderio crescente da Indústria. Saint-Simon, percebera o verdadeiro sentido da Revolução. "A Nação, dizia êle, estava dividida em três classes: os nobres, os burgueses e os industriais. Os nobres governavam. Os burgueses e industriais os pagavam" (113). A Revolução tinha que ser, por-

(110) - Ibidem, p. 232.

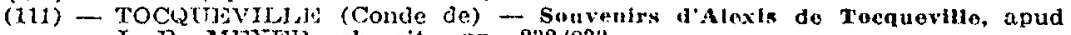
J. $P$. MEIER, ob. cit., pp. $232 / 23 \%$.

(112) - CHATEATiBRIAND. - Géne du Chrigtianisme, apud J. P. MEYER, ob. cit., p. 235 .

(113) - SAINT-SIMON. - Catúchisme des Industriels, ler cahter, dezembro de 1823, apud C. BOUGLE, L'Oeuvre do Saint-Simon, p. 160. 
tanto, obra da classe média. "Não foram os industriais que fizeram a Revolução; foram os burgueses, isto é, os militares que eram nobres, os legistas que possuiam herança, os rendeiros que não possuiam privilégios" (114). A Revolução abolira o feudalismo, mas conservara a aristocracia. As propriedades desta valorizaram-se durante o bloqueio que os aliados fizeram a Napoleão. Livres da concorrência inglêsa, os industriais aperfeiçoaram as suas máquinas e houve, assim, grande desenvolvimento indútrial.

Todos êstes acontecimentos não têm apenas um caráter econômico mas influem na transformação dos valores morais. SaintSimon é por isso, na sua época, o primeiro a compreender claramente o sentido da revolução. Tôda sua obra, como diz Gouhier, é uma meditação da revolução. Das Lettres d'un habitant de Géneve à ses Contemporains, que é de 1803 , até o Nourveau Christianisme que é de 1825, Saint-Simon estuda a história para dela tirar uma definição da Revolução. Comte conviveria com Saint- Simon durante êsse periodo.

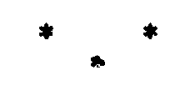

Embora depois de sua ruptura com Saint-Simon, Augusto Comte negasse ou procurasse sempre mostrar os males que the advieram de sua colaboração com o conde, a influência dêste é bem marcada sôbre a doutrina do filósofo. Ambos estão ligados à Revolução pelas suas próprias vidas. Todavia, a Revolução é diferentemente considerada por êles. Augusto Comte não sofrera: como seu mestre, o drama que obrigara o nobre Saint-Simon a transformar-se no cidadão Bonhomme e que, mais tarde dêle faria novamente o Conde Henri de Saint-Simon. Augusto Comte nascera numa família burguesa. Seu pai, funcionário da receita do departamento do Hérault, pertericia à classe dos que haviam lucrado com a Revolução. Nascido em 1798, a infância e a adolescência de Augusto Comte enchem-se de recordações da "sublime insurreição" (115). Burguês, letrado e romântico - e além disso ambicioso - Augusto Comte seguirá com prazer as fantasias do velho Père Simon. Sensível à glória literária e com marcadas veleidades de mando, jovem escritor político a 300 francos por mês, o moço talvez sonhasse em dirigir, livre da influência do velho Conde, a consciência, política dos homens de Estado de seu tempo... (116). Aliás, na tradição da cultura francesa, o homem de letras esteve sempre ligado à política (117). Menos intelectualizado do que o

(114) - Ibidem, p. 181.

(115) - COMTE (A.). - Lettres a Valat, p. 6.

(116) - GOUHIER (E.). - Ia Vle d'Auguste Comte, p. 135.

(117) - MAYkiR (J. P.). - Trayectoria del Pensamiento Politico, p. 234. 
discipulo - tão marcadamente professoral - Saint-Simon que conhecera o mundo dos negócios e andava envolvido na vertigem das negociatas que a Revolução proporcionara - que se desprendera completamente dos hábitos feudais (118), - compreendera, logo, a importância do fator econômico da nova fase histórica que os acontecimentos de 89 abriram.

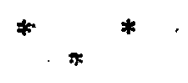

"O positivismo comtiano, escreve Jean Delvolvé, é um vasto poema do destino humano" (119). De fato, Augusto Comte, quando empreendeu a sua obra, espécie de novissimum orǵñnum da ciência - não pretendeu apenas fazer obra de lógica, mas encontrar materiais que lhe servissem para a: construção de uma "síntese capaz de fornecer princípios dirigentes à atividade política e moral" (120). O vasto poema de Augusto Comte poderíamos resumí-lo talvez numa frase do filósofo: generalizar a ciência e sistematizar a arte social (121).

Estas duas fases inseparáveis de u'a mesma concepção serăo estudadas no Discours Préliminaire sur l' Ensemble du Positivisme indicando-se aí "primeiramente o espírito geral da nova filosofia e, em seguida, a sua necessária conexão com o conjunto da grande revolução de que ela vem dirigir a terminação orgânica" (122). Este Discurso é, pois, uma das peças mais importantes da segunda fase da doutrina de Augusto Comte e é nele que encontramos como que a "orquestração" doutrinária de Comte. Escrito em 1848, - Discurso corresponde aos mais: altos pontos de sis'ematização do pensamento de Comte. Não sabemos se é possível dizer que êste discurso marque a transição decisiva de Comte entre a fase científica e a política, pois há entre as duas partes da filosofia de

(118) - COMTE (A.). - Jettres a Valat, p. 51. Na carta de 15 de malo de 1818. Comte to referir-se a Saint-Simon, diz: "h o melhor homem que já conheci. F aquéle cuja conduta, cujos escritos e sentimentos são os mais sefuros e cocrentes. Saint-Simon renunciou di. nobreza. e abjurou intelramente todos os hábitos feudais". preclso notar, todavia. Que em janeiro de 1815, Saint-Simon dirigia uma carta a Luiz XVIII. em que aparecen estes trechos: "Os estudos filosoficos e polfticos aos quais consagrei minha vida, que até o presente não tiveram senão uma direção vaga, têm hoje por fim único reforçar o cetro nas mãos dos Jourbong e consolidar a monarquia que $\uparrow$. Majestade reconstruiu", apud H. GOUHIER, La Vie d'Auguste comte, p. 28. Para ele, os nobres. - escrevia a um dos sobrinhos -, estão destinados a uma missão superior. Mas, para isso ó mister que se voltem resolutamente para o futuro e ajudem, com a sua inteligencia, a reconstruçäo que se faz necessuria". Cf. C. BOUGLA, L'oeuvre de Saint-Bimon, p. VI.

(119) - Dislvolvs (.lean). - Keflexions sur in Pensé Comtionne, p. 54.

(120) - Ibidem, p. 55.

(121) - COMTE(A.). - Discours Próliminairo sur l'Ensomble du Positivismo. in Systeme de Politique Positive, vol. T. D. 3.

(122) - Ibldem. 
Augusto Comte, uma perfeita unidade. O Discurso vai nos oferecer agora uma perpectiva geral da obra de Comte. Nessa obra estão definidos os serviços que a doutrina pode prestar e a função que está fadada a realizar.

A filosofia de Augusto Comte é interessante sobretudo no seu aspecto prático, isto é, moral e político. Em carta a Henry Edger, o filósofo escrevia que o "positivismo exalta os instintos altruistas e comprime tôdas as inclinações egoistas. Ele vem - acrescentava - regular a vida humana, particular ou pública que se encontra em plena anarquia universal" (123). O caráter prático da doutrina comtiana realiza-se plenamente ao estender-se ao domínio da moral. Comte ignora todos os princípios que ultrapassam a experiência histórica e social, tôda perspectiva que vai além da vida terrestre. $\mathbf{R e}-$ belado contra tôda a autoridade extra-humana, tudo para êle tem origem e fim no humano. A moral positiva: afastará de si, portanto, qualquer fundamentação abstrata. As filosofias tradicionais também tentaram sistematizar a existência humana. Os filósofos, com êste fito, procuram intervir na marcha dos fenômenos ligados à existência, prevenindo-lhe as incoerências, evitando-lhe os retardamentos, enfim, exercendo a sua inteligência em face da realidade viva, espontânea que é a vida. $\mathbf{E}$ ' "a realização contínua desta indespensável intervenção que contitui o domínio essencial da política", diz Comte (124).

Mas uma intervenção assim só pode ser eficaz quando decorre de uma doutrina filosófica. A tarefa da filosofia consiste, portanto, em "coodenar entre si tôdas as partes da existência humana, afima de reduzí-las a uma verdadeira unidade" (125). Este trabalho incumbe, porém, à política positiva, parte integrante da doutrina positiva. O filósofo e o político trabalham juntos. No entanto, "se a filosofia tentasse influir diretamente sôbre a vida ativa, de outro modo que pela sistematização, ela usurparia viciosamente, diz Comte, a missão necessária da política, único árbitro legítimo de tôda evolução prática. (126). O liame entre estas duas atividades, ou como as chama Comte, funçöes, reside na existência de uma moral sisto mática que "constitui naturalmente a aplicação característica da filosofia e o guia da política" (127). E esta coordenação seria simplesmente quimérica se não abrangesse o tríplice domínio da especulação, da afetividade e da ação.

A sistematização teológica, emanava do afetivo e deve o seu fastígio - e também a sua decadência - a essa origem. A filosofia moderna, positiva, ocupa-se com os três aspectos acima descritos. Não é, porém, uma coordenação exclusivamente subjetiva como foi

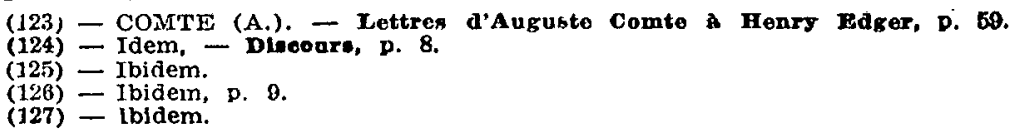


a teológica, nem o poderia ser em virtude "do destino necessàriamente objetivo que caracteriza a existência prática, segundo a sua invencível realidade" (128). A filosofia teológica deveu a sua impotência precisamente ao fato de não conseguir integrar a existência no seu aspecto ativo. A especulação filosófica sofreu sempre, dêsse modo, mutilações que lhe advieram da ausência de uma consideração integral da natureza humana. A sistematização social era imposssível na concepção teológica $e$, do mesmo modo o foi numa coordenação metafísica. "Ao tempo ainda do seu maior esplendor escolástico, a sistematização ontológica nunca saiu do domínio especulativo (e ficou) reduzida a contemplação abstrata de uma evolução puramente individual, pois que o espírito metafisico é radicalmente incompatível com o ponto de vista social" (129). Ao contrário, a filosofia emana da vida ativa e, por essa razão, tem uma aptidão característica para sistematizar a existência prática (130). Sòmente o espírito positivo, em virtude de sua natureza eminentemente relativa, pode representar convenientemente tôdas as grandes épocas históricas como outras tantas fases determinadas de uma só evolução fundamental, em que cada uma resulta da precendente e prepara a seguinte segundo leis invariáveis que fixam a sua participação especial, a progressão, comum de maneira a permitir sempre, sem inconseqüência ou parcialidade, de prestar uma exata justiça filosófica a tôdas as cooperações. Embora êste privilégio incontestável da positividade racional deva, desde logo, parecer puramente especulativa os verdadeiros pensadores aí reconhecem logo a primeira fonte necessária do ativo ascendente social reservado finalmente a nova filosofia" (131).

Afim de que a coordenação positiva se processe integralmente é mister, porém, que ela não deixe de atender ao sentimento. Ainda uma vez é o sistema teológico um exemplo que serve para Augusto Comte. Referindo-se à fase teológica da história, diz Comte que, apesar de sua evidente caducidade, ela conservará, ao menos em princípio, algumas pretenções legítimas à preponderância social enquanto a nova filosofia não a despojar também dêste privilégio fundamental" (132). A filosofia positiva não se consolidará, portan-

(128) - Ibldem, p. 10.

(129) - Iblaem.

(130) - “O primado da açăo reforça a autoridade e a supremacia da ciência desinteressada, da ciencia pura. Mas entre esta e a aplicacão, há quase sempre um hiato para o entendimento humano: uma zona de impotencia que assinala o fracasso da nossa razto, uma distancia intransponivel para as nossas deducōes racionais. Impotêncla do nosso espirito adatado ao simples e que a complexidade fatiga muito depressa. O que maravilha é a engenhosidade com a qual a raça humana, procura ultrapassar este obstáculo térico. Em todos os domínios, os artifícios práticos são extraordinàriamente fecundos; a própria origem das ciências näo é inseparável do impulso das técnicas: em toda a parte as necesslaades da acão humana suscitam e fecundam o genlo inventivo". Cf. PIERRE DUCASSt. - Eskai sur les Origines Intuitives du Positivisme, p. 52 .

(131) - A. COMTU, Discours Prollminalre sur 1'Rsprit Positie, in Traits d'Astronomle Populalre, pp. 61/62.

(132) - COMTE(A.). - Disconrs Prolliminairo our l'Rnsemble du Positiviame, in Bystèmo de Politique Positive, vol. I, pp. $12 / 13$. 
to, na opinião de Comte, enquanto não tiver a sua estruturação ma ral, cuja base se encortra na afetividade. Se a positividade parece pouco adequada ao sentimento, o que era natural em virtude de sua própria origem, estendida agora ao domínio do social, perde os vícios que lhe eram próprios. A nova filosofia destina-se a ser mais moral que intelectual e fazer da vida afetiva o centro de sua sistematização, afim de "representar exatamente os direitos respectivos do espírito e do coração na verdadeira economia da natureza humana, quer ela seja individual ou coletiva" (133).

$O$ positivismo afirma dêste modo, que a felicidade individual e pública dependem mais do coração do que da inteligência, dissipando a pretenciosa supremacia que se atribuia à inteligência. Gustave Belot ao estudar a moral de Comte, num interessante artigo da Revue Philosophique, notava que é "impossível, sem injustiça, esquecer (as concepções morais da filosofia de Comte) para apreciarthe o conjunto, e é singular, acrescentava, que os primeiros discípulos ou apologistas de Comte tenham acreditado servir sua memória e consolidar sua filosofia, pondo de lado, precisamente aquilo sôbre que êle fazia maior empenho, isto é, tôda a filosofia prática que, qualquer que seja o seu valor intrínseco, explica e até descuipa, em parte, as lacunas e as fraquezas de sua teoria da ciência" (134). Assim, "nem a filosofia metafísica que consagra espontâneamente o egoismo, nem mesmo a filosofia teológica, que subordina a vida real a um destino quimérico, puderam fazer ressaltar o ponto de vista social, como "o fará, devido à sua natureza, esta filosofia nova que o toma por base universal da sistematização final" (135). Só quando uma educação verdadeira tiver conseguido "familiarizar os espíritos modernos com as noções de solidariedade e de perpetuidade que a contemplação positiva da evolução social sugere, é que, espontâneamente, se sentirá a superioridade moral de uma filosofia que liga cada um de nós à existência total da humanidade, considerada no conjunto dos tempos e dos lugares; a religião, ao contrário, não podia reconhecer senão indivíduos passageiramente reunidos, todos absorvidos por um destino puramente pessoal e cuja vã associação final, vàgamente relegada ao céu, apenas oferecida à imaginação humana um tipo radicalmente estéril, devido à falta de uma finalidade apreensivel" (136).

A moral de Comte, terá assim, um caráter de arte educativa, de técnica de vida. A moral positiva não é especulativa, abstrata. Ela é, como diz Comte no Catecismo, " a ciência por excelência, pois que é, ao mesmo tempo, a mais útil e a mais completa" (137).

\footnotetext{
(133) - Ibidem, p. 14.

(134) - BELot (Gustave). L La Morale de Comte, in Rovue Philogophique, dezembro de 1903 .

(135) - COMTe(A.). - Cours do Phlosophio Positive, t. VI, p. 531.

(136) - Idem, p. 532.

(137) - COMTE (A.). - Catedsrao Positivista, p. 204.
} 
O positivismo considera, como se vê, a moral sob o ponto de vista social. Comte não se preocupou, porém, em fundamentar uma moral teórica como os moralistas do passado. A sociologia (e dirímos mais: a psicologia), fornecem-lhe a sistematização necessária à obra moral. No entanto "acontece com a sua moral, o que se đá com a sua filosofia do real: está subentendida ou melhor, está esparsa em tôda a sua obra $\epsilon$, por isso mesmo, se apresenta flutuando nos seus contornos e muito pouco definida no seu mét'odo ou nos seus princípios" (138).

As leis sociológicas constituem verdadeiras regras de conduta para Augusto Comte. A sociologia irá prolongar-se assim, numa especie de arte de viver, numa verdadeira técnica da ação moral e politica. A sociologia será, portanto, para os fenômenos morais o que a física é para os fenômenos da natureza inorgânica: é ela que realiza a coerência lógica necessária à própria unidade moral.

Mas o trabalho da inteligência não é suficiente para criar o liame social necessário à organização da sociedade. "As mais sábias combinações intelectuais podem apenas organizar o egoismo e o isolamento. De um modo geral, a inteligência apenas .ordena, sistematiza: ela não engendra. O que cria é o coração. $O$ coração está necessàriamente na origem desta criação que é o organismo social" (139). Todos os grandes pensamentos, já o dissera Vauvenargues, vêm do coração e tôda a unidade deriva de um sentimento ao qual se subordinam os nossos pensamentos (140).

A doutrina positiva erige, dêste modo, como dogma fundamental, ao mesmo tempo filosófico e político, a preponderância do coração sôbre o cspítito. Este dogma é condição essencial da unidade humana. Por isso, o "positivismo - escreve Augusto Comte - concebe a arte moral como consistindo em fazer, tanto quanto possivel, prevalecer os instintos simpáticos sôbre os impulsos egoistas, a sociabilidade sôbre a personalidade. Esta maneira de considerar o conjunto da moral é própria à nova filosofia, a única que sistematiza os progressos realizados entre os modernos numa verdadeira teoria da natureza humana, tão imperfeitamente representada pelo catolicismo" (141).

(138) - CANTECOR (G.). - Comto, p. J.20. Este carater flutuante da "fllosofia moral" de Augusto Comte suscitará entre os seus seguidores, por essa razāo, um largo e variado comentário. Nos números da Rerue Occidentale abundam, alias sintomaticamente os trabalhos relativos a moral positiva.

(139) - BOUTROUX (E.). - Bcience et Religion dans la Phllosophie Contemporaine, $\mathrm{D}$. 52.

(140) - COMTE(A.). - Cateclemo Positivlsta, trad. M. Lemos, p. 47.

(141) - COMTe(A.). - Discours Préliminaire sur l'ensemble du Positivismo, pp. 91/92. "Augusto Comte reconhece que a moral teologica sempre fol superior a todas aquelas que a especulação filosófica e a razão produziram. A religião implica, sem aparelhamento cientifico, uma psicoJogia muito mais exata do que a dos filósofos. Ila diz respeito ao homem concreto e real. Não se fiude sobre a importancia relativa de suas faculdades e sôbre a fôrça respectiva de suas inclinações e paixōes. O padre $€$ melhor conhecedor dos homens que o metafísico" L. LAVT-BRUHL, La Philosophio d'Auguste Comto, p. 351 
Se a biologia nos revela a preponderância da vida orgânica, a sociologia nos indica o ascedente dos sentimentos em nossa natureza, o que aliás, o catolicismo considerava como estranho à nossa constituição, e sòmente inspirado por uma graça sôbre-humana que não comportava 'nenhuma lei. "O grande problema consiste, pois, em investir artificialmente a sociabilidade com a preponderância que possui a personalidade. Sua solução repousa sôbre um princípio biológico, o desenvolvimento das funções e dos orgãos pelo exerćcio habitual e sua tendência à atrofia pela inação prolongada" (142). Esta arte moral de Comte lembra, sob certos aspectos, Platão. A moral completa o trabalho da sociologia. E também - elo entre esta e a política. "Assim aparece uma disciplina nova, à qual convém o nome de síntese total, a moral, intermediária entre a sociologia e suas aplicações práticas que constituem a política, verdadeira teoria do indivíduo humano considerado no seu tríplice destino de ser pensante, de ser afetivo e de ser ativo, ao mesmo tempo: crítica, estética e étíca. Pouco importa agora que esta ciência nova, a mais particular e a mais complexa de tôdas, tenha aparecido a Comte como uma espécie de combinação, aliás mal determinada, da biologia e da sociologia (Cf. Système, II, 438). Seu verdadeiro sentido é, desde o instante em que se tem em conta que a orientação geral da sociologia positiva é a predominância da ordem sôbre o progresso, do esiático sôbre o dinâmico, a descoberta das condições permanentes da existência social, a definição da inteligência como instrumento da sociabilidade. A insuficiência enfim de tôda a especialização científica, deviam conduzir Augusto Comte à análise direta, completa, interna, da natureza humana" (143).

Mas qual é o pensamento de Augusto Comte em relação a natureza do homem? Não é fácil situar bem êste problema, na filosofia comtiana.

O homem é um produto do meio e dos seus impulsos. A natureza humana é, assim, estudada pela biologia e pela sociologia. Comte é um admirador de Cabanis que, na sua opinião, foi um dos primeiros a conceber, de modo positivo, os fenômenos intelectuais e morais. Admira também a Gall. Não podemos, no entanto, afirmar que aceitasse inteiramente as idéias dêstes dois autores. to, porém, que a psicologia para Comte passou por várias vicissitudes antes da elaboração do Sistema da Politica Positiva e, por isso mesmo, é vaga e bastante imprecisa (144), dissolvendo-se inteira-

(142) - COMTE(A.). - Discours, p. 92..

(14.3) - HUBERT(R.). - La Theorie do la Connaisance chex Anguste Comte. in Revue Philonophique, 1925, pp. 270/271.

(144) - "A psicologia, que no Curso de Fllosofia Positiva, era biologlca, por essencia, e acabava simpiesmente na sociologia, transforma-ge, na PoIítica Positiva, em sociológica por essência e somente é, secundariamente, biológica. A partir de 1846 Conte tomou nova consciência do seu pensamento. Durante os cinco anos que se vāo seguir, éle mão cesa de trabalhar no seu quadro cerebral". (Ce. L. LEV-BRUHL, Ir Philosophie d'Auruste Comte, p. 234). 
mente na sociologia, na derradeira fase da doutrina. Uma inspiração sociológica controlada pela apreciação zoológica, tal é o princípio geral a que obedece a psicologia de Comte (145).

$\mathrm{Na}$ introdução da Síntese Subjetiva, logo nas primeiras linhas, há um verdadeiro programa moral e político, em que se percebe uma total inspiração sociológica. "Subordinar o progresso à ordem, a análise à síntese e o egoismo ao altruismo, tais são, diz Comte, os três enunciados, prático, teórico e moral do problema humano" (146). A solução dêstes problemas é, no entanto, uma só. Tôdas estas modalidades do problema humano são ultrapassadas pelo problema moral. A ordem supõe o amor e a síntese não se pode realizar a não ser pela simpatia; a unidade teórica e a unidade prática são, pois, impossíveis sem unidade moral" (147).

Viver para outrem é a grande máxima moral do positivismo. O altruismo é o têrmo natural do progresso sentimental. E pela afeição familiar que o homem sai da sua personalidade primitiva, se eleva à sociabilidade. "A evolução individual do sentimento social, começa na família pelo inevitável desenvolvimento da afeição filial, primeira fonte de nossa educação moral, onde surge o instinto da continuidade, e, por conseguinte, a veneração pelos predecessores; é assim que cada novo ser se liga, desde logo, ao conjunto do passado humano" (148). A afeição fraterna completa êste esbôço inicial. A nossa educação moral prossegue na vida conjugal, cuja mutualidade e indissolubilidade de vínculo é, a seu ver, garantia de plenitude do devotamento (149). Desta união resulta a última afeição doméstica, "a paternidade, que determina nossa iniciação espontânea na sociabilidade universal, ensina-nos a querer os nossos sucessores. Estamos assim ligados ao futuro como antes - estávamos ao passado" (150). E pela educação doméstica que aprendemos a ordenar os nossos sentimentos, os nossos instintos egoistas. Eela família que se faz a ligação entre a existência pessoal e social. Enfim, o verdadeiro caráter da educação moral depende da submissão do indivíduo à sociedade (151).

E é, através da moralidade social, precisamente, que Comte pretende chegar a regeneração da Humanidade. Só o Amor da Hu-

\footnotetext{
(145) - Cf. A. COMTE, Système de Politique Positive, vol. I, p. 673. Cf. alnda 0 quadro de p. 726 desta obra.

(146) - COMTE (A..). - Synthese Bubjective, p. 1

(147) - Ibidem.

(148) - A. COMTE, Discours, p. 95.

(149) - T curioso notar a contradição existênte entre a đoutrina e a vida real de Augusto Comte em relaça à vida conjugal. Tanto o filósofo como Clotilde de Vaux sopreram com os vipculos conjugais. Clotilde, no en. tanto, na sua novela Lucia (que esté publicada no vol. I, do systeme de Folitiquo Positivo) rebela-se contra esses vínculos e nela apresenta uma defesa do divórcio. Outro fosse o desfécho da paixäo de Comte por Clotilde, outra, possivelniente, teria sjdo a sua atitude em relaçio aos vínculos indissoláveís do matrimonio. Cf. CHARLES DE ROUVRE. L'Amourcase Histolre d'Augusto Comte et do Clotilde do Vaux.

(150) - COMTE (A.). - Discours, p. 95.

(161) - No que diz respeito as regras da moral Individual, a doutrina de Augusta Comte quase nada de novo apresenta. Comte, a este respeito limita-se a prescrever o que a moral tradicional recomenda.
} 
manidade renovará a conduta moral. Para que a regeneração sonhada por Augusto Comte possa se processar, mister é que o positivismo se apoie, não nas classes, espirituais ou temporais, que até 1848 participaram do govêrno da humanidade. Tôdas essas classes têm preconceitos e paixões que impedem $a$ reorganização intelectual e moral necessária à nova era. "Um ativo egoismo aristocrático entrava ordinàriamente a preponderância real do sentimento social, princípio supremo de nossa regeneração. Não se deve contar com as classes cuja dominação foi para sempre destruida no início da crise revolucionária. Devemos contar - escreve Augusto Comte - com uma repugnância quasé tão real, embora melhor dissimulada, entre aquelas (classes) que obtiveram 0 ascendente social, que ambicionavam há muito tempo. A burguesia que se apoderou do govêrno interessa-se mais pelo poder do que pelo seu destino e exercício. Aliás, uma regeneração social é tão temida pelas classes médias quanto o é pelas antigas classes superiores (152). Apesar da diversidade que existe entre os sábios e os proletários, diversidade que é mais aparente do que real, o mesmo espírito domina, diz Comte, os positivistas e os proletários (153). "Os dois gêneros de espírito apresentarão, cada vez mais, o mesmo instinto do realidade, uma semelhante predileção pela utilidade e uma igual tendência para subordinar os pensamentos de detalhe às visóes de conjunto (...) Estas classes extremas oferecem, aliás, disposições equiivalentes para com a classe intermediária que, sede necessária da preponderância temporal, tem sob sua dependência normal a sua comum existência pecuniária" (154).

A classe proletária é, na opinião de Augusto Comte, mais do qualquer outra, aquela que se destina a compreender, e sobretudo a sentir a moral real, embora ela seja incapaz de sistematizá-la. A regeneração social sòmente poderá ser assim realizada quando o proletariado se tornar o auxiliar indispensável do poder espiritual.

O positivismo para realizar o seu destino moral e político, deve dirigir-se ao proletariado, pois sòmente êste é capaz de se tornar um auxiliar decisivo dos novos filósofos. A superioridade da classe proletária é evidente sobretudo no que diz respeito ao sentimento social. Em relação a êste, "os proletários ultrapassam até os verdadeiros filósofos, cujas tendências, por demais abstratas, muito ga-

(162) - COMTE (A.). - Discours Proliminsiro sur l'Engemble do Positivismo, p. 128. Uma ou outra destas classes, diz Comte, apenas pretende prolongar. tanto quanto possivel, sob novas formas, o "sistema de hipocrisia teológica que constitui agora o anloo resto efetivo do regime retrógado" (Ce. A. COMTE, Dlscours Préliminairo aur l'Ensemblo du Poitivisme, p. 129).

(153) - Este entugiasmo pela classe proletária, poderia fazer supor que existem grandes analogias entre a doutrina de Marx e a de Comte. Mas elas Bão mais aparentes do que reais. - Ce. PAUL LABERENNE, Efficacits Politique et Bocialo du Positivinme et du Marrisme, in $A$ la lnmiare dn Marxismo $t$. II, p. 97 .

(164) - COMTE (A). - Discours, p. 130.1 
nhariam no contacto diário com uma nobre espontaneidade popular" (155).

Isto nos levaria a indagar se haveria analogia entre as doutrinas de Comte e de Karl Marx? Há, evidentemente algumas analogias e semelhanças entre as duas doutrinas. Os seus fundadores viveram na mesma época e, embora de formação diversa, ambos perceberam que a solução dos problemas da sociedade moderna sòmente poderia ser encoñtrada no sentido socialista. A organização social preconizada por êles é, porém, quer nas suas bases como nas suas finalidades, muito diversa. $O$ degtino indicado à classe proletária por Comte é mais moral do que político. "A principal melhoria, a que deve logo desenvolver e consolidar tôdas as outras, consiste no nobre ofício social conferido diretamente aos proletários, doravante erigidos em auxiliares indispensáveis do poder espiritual. Esta imensa classe, que desde o seu nascimento na Idade Média ficara exterior à ordem moderna, aí toma então a verdadeira posição que convém a sua natureza própria e ao bem comum. Ás suas funções especiais, todos os seus membros juntam enfim uma alta participação hebitual na vida pública destinada a compensar os inconvenientes inevitáveis de uma situação privada. Longe de perturbar a ordem fundamental, uma tal cooperação popular constituirá a mais firme garantia pelo fato precisamente dela não ser política, mas moral. Tal é, assim, a transformação final que o positivismo opera na maneira pela qual o espírito revolucionário concebeu até aqui a intervenção social dos proletários. À tempestuosa discussão dos direitos, nós substituimơ a pacífica determinação dos deveres aos debates inútelis acêtca da da posse do poder, o exame das regras relativas ao seu sábio exercício" (156). Não é portanto a forma de govêrna que interessa Augusto Comte mas a reorganização social, as relações de classes e os "direitos e deveres de cada uma delas na prcdução e repartição dos bens" (157).

(155) - COMrIS (A.). ob. cit., p. 137.

(156) - COM'rE ( $A_{t}$ ). ob. cit., pp. $150 / 151$ (os grifos são nossos).

(157) - CANTECOR (G.). - Comte, p. 49.

Augusto Comte, referindo-se ao comunlamo, assim se expressa, no Discours Prsliminaire sur l'Enmemble du Poeftivisme: "Une superficielle appréciation de la situation actuelle represente d'abord nos proletaires comme très éloignés encore d'une semblable disposition. Mais, d'après une ctude mieux approfondie, on peut assurer que l'expérience même gu'ils accomplissent nujourd'hui sur l'extension des droits politiques, acheveri bientôt de leur manifester l'inanité d'un remède aussi peu conforme a leur voeux naturels. Sans faire une abdication formelle, qui sembleralt contraire a leur dignite sociale, leur sagesse fnstinctive ne tardera pas a determiner une désuétude encore plus decisive. Le positivisme les convalncra alsément que, si le pouvoir opirituel doit se ramifler partout pour atteindre pleinement son but social, le bon ordre exige, au contraire, la concentration habituelle du pouvoir temporel. Cette conviction résultera surtout d' une aaine appréclation do la nature essentiellement morale des difficultés fondamentales quil préoccupent s! justement nos prolétulres. Ils ont déja falt à cet égard, un par apontané, dont l'importance est encore trop peu sentie. Une celebre utople. qui a'y propaga rapidement, leur sert, faute d'une mellleure doctrine, a formuler aujourd'hui lour maniero propre de concevoir"la principale 
Comte procurará resolver a questão social apelando sobretudo para a moral e para a educação. "O positivismo é levado a sistemar tizar o princípio do comunismo sôbre a natureza social da propriedade e sôbre a necessidade de regulá-la" (158). Nada existe aliás que o positivismo não tente sistematizar e regulamentar. "O comunismo elas fôssem as únicas fôrças sociais que estivessem hoje mal repartidas e mal administradas" (159). O positivismo ao contrário, possui uma aptidão característica para resolver moralmente as principais dificuldades sociais (160). Esta aptidão, no entanto, nunca tomou uma forma ativa, verdadeiramente prática.

\title{
, J. CRUZ COSTA
}

\author{
Professor da Cadeira de Filosofla \\ (U. S. P.)
}

(Continua no próximo número).

question sociale. Quolque l'expérlence resultée de la première partie de la revolution ne les alt point desabusés entlèrement des lllusions politiques, el!e les a conduits a sentir que la proprlété leur importait da. vantage que le pouvolr proprement dit. En étendant Jusque-la le grand probleme social, le communisme rend aujourd'hui un service fondamental, qui n'est pas neutrallsé par des dangers temporalres inhérents a ses fornies métaphysiques. Aussi cette utople dolt-elle etre soigneusement distinguée des nombreuses aberrations qul fait eclore notre anarchie splrituelle, en appelant aux plus difficlies speculationg des esprits incapables ou mal preparés. Ces vaines théries sont si peu caracterisees qu'on est condult à les désigner par les noms de leurs auteurs. Le comnunisme, que ne porta le nom de personne. n'est polnt un produit accessoire d'une situation exceptionelle. Il y faut volr le progres spontane, plutot affectle que rationnel, du véritable esprit révolutionnaire, tendant aujoura'hul a se préoccuper surtout des questions moraleg en rejetant au second rang les questions, politiques proprement dites. Sans doute, la solution actuelle des communistes reste encore escentiellement politíque, comme chez leurs prédecesseurs, puisque c'est aussi par le mode de possession qu'jls pretendent regler l'exercice. Mais la question qu'lis ont enfin pose exige tellement une solution morale, ara solution politique serait \& la foig ai insuffisante et si subversive. qu'elle ne peut rester a l'oräre du jour sans faire blentot prevalolr l'issue decisive que le positivisme vient ouvrir a ce besoin fondamental, en présidant à la régération finale des oplntong et des moeurs. Pour rendre justice au communisme, on doit surtout y apprécler les nobles sentiments quil le caracterisent, et non les vaines theorles qui leur servent $d^{\prime}$ organes provisoires, dans un milleu ou $11 \mathrm{~g}$ ne peuvent encore se fornuler autrement. En s'attachant à une telle utople, nos prolétalres. tris peu metapinsiques, sont loin d'accorder a ces doctrines autant d'importance que nos lettrés. Aussitot qu'lls connaltront une mellleure exprcssion de leurs vocux légitimes, 11 n'hesiteront pas a preferer desnotions claires et reelles, susceptibleg d'une efficacité palaible et durable, a des vagues et confuses chimères, dont leur ingtinct sentira bientót la tendance nnarchique "A. COMTE, Discours, pD. 151/153.

(158) - COMTE (A.). - Dlscours, p. 154. "L'unanime réprobation qu'inspirent ces utopies doit surtout partout alsposer au positivisme. qui désormala peut seul préserver l'Occident de toute grave tentative communiste" (Discoure, p. 154).

(159) - COMTE (A.) ob. clt., p. 105.

(160) - COMTE (A.) ob. cit., D. 106. 